\title{
Growth Performance and Survival Rate of Clarias gariepinus Fed Lactobacillus acidophilus supplemented diets
}

\author{
*OlaniyiAfolabiOpasola, Solomon.O Adewoye and Olatunde.OFawole \\ Department of Pure and Applied Biology, LadokeAkintola University of Technology,P.M.B, 4000, Ogbomoso.
}

\begin{abstract}
The aim of this work was to evaluate the usefulness of Lactobacillus acidophilus as a potential probiotic in fish farming using C. gariepinus as biological model. The experimental fish were divided into four groups, the first group was fed on diet supplemented with $0.5 \mathrm{ml}$ of $L$. acidophilusand designated as Group A ,the second group was fed on diet supplemented with $1 \mathrm{ml}$ of L. acidophilusand designated as Group B the third group was fed on diet supplemented with $1.5 \mathrm{ml}$ of $L$. acidophilusand designated as Group $C$ and the fourth group was served as control fed on $L$. acidophilus-free diet. The final weight of the groups that received $L$. acidophilus were not statistically different with the following mean values $390 \mathrm{~g}, 395 \mathrm{~g}$ and $400 \mathrm{~g}$ for Group $A, B$ and $C$ respectively but the mean weight of the control that does not receive $L$. acidophilus was $350 \mathrm{~g}$ which is statistically different from the groups that received $L$. acidophilus. The result obtained revealed that percentage of fish that survived in the groups fed with L. acidophilus were 84\%, 88\% and 88\% for Group A,B and C respectively and $72 \%$ for the control that was not fed with L. acidophilus the corresponding percentage mortality was calculated to be $16 \%, 12 \%, 12 \%$ and $20 \%$ respectively. The result indicated that percentage mortality was very high in the control group that was not fed with L. acidophilus. This study was able to establish that L. acidophilus could be a good probiotic candidate in fish production because of its ability to enhance growth of C. gariepinus.
\end{abstract}

Key words: antibiotics, probiotics, , growth, aquaculture, environment

\section{Introduction}

Due to the prevalence of antibiotic resistance in aquaculture there is an urgent need in aquaculture development for microbial control strategies since disease outbreaks are recognized as important constrains to aquaculture [1].One of the methods gaining recognition for controlling pathogens within the aquaculture industry is the use of beneficial or probiotics bacteria $[1,2,3]$. The use of antibiotic to treat or control disease in aquaculture has been reported to disrupt the fish intestinal microflora [4] pollute the environment, increase cost of production and ultimately cause prevalence of antibiotic resistance [4]. To keep a sustainable growth pattern and health management, strategies must go beyond antibiotics and chemotherapeutics, which create resistant bacteria and immunosuppression in the host [5].

The antibiotic resistant bacteria have been reported to be capable of proliferating after an antibiotic has killed off the other bacteria and they can also transfer their resistance genes to other bacteria that have never been exposed to antibiotic [2]. Resistance mechanism can arise in one of these two ways: chromosomal mutation or acquisition of plasmids. Several bacteria pathogens can develop plasmid mediated resistance. At the high population densities of bacteria found in aquaculture ponds, transfer via viruses and even direct transformation from DNA observed to the particles in water or on sediment surface could all be likely mechanism of genetic exchange [6]

In view of the above, the development of non-antibiotic agent is one of the key factors for health management in aquaculture. One of the most significant technologies that evolved in response to disease control problem is the use of probiotics. The application of probiotics is prevalent in United State of America, China, Japan, Indonesia, Thailand and European countries with commendable achievements. However, although the Nigeria aquaculture industry is expanding the application and development of probiotics is very meagre when compared to other countries. This study was primarily carried out to investigate the growth performance of $C$. gariepinus fed L. acidophilus supplemented feed for 90 days.

\section{Experimental Fish AndHusbandary Conditions}

\section{Materials And Methods}

This study was conducted at the fish shed of Department of Pure and Applied Biology, LadokeAkintola University of Technology, Ogbomoso, Nigeria. About 300 African Catfish (Mean initial weight $32 \pm 0.85 \mathrm{~g}$ ) purchased from a local fish farm in Ibadan were used in this study. Fish were acclimatized to laboratory conditions for fourteen days (14 days) and fed a commercial feed, before the commencement of the study.Twenty five (25) fish were randomly distributed in each of thirty (30) litres capacity of plastic container already washed with acetic acid to remove contaminants, each of the plastic containers was filled with fifteen 
(15) litres of water. Two replicate groups of fish were maintained for each feed treatment under a natural photoperiod for an approximately 12/12hours light/dark cycle.

\section{Isolation AndCharactetization Of Lactobacillus Acidophilus}

Lactobacillusacidophilus was isolated from a popular commercial yoghurt in Ogbomoso. The yoghurt was homogenized in sterile distilled water. The homogenized sample was diluted serially up to 10 fold in sterile water and then inoculated on demanRogosa and Sharpe (MRS, Oxoid, England) agar plates by pour plate method . MRS agar plates were incubated at $37^{\circ} \mathrm{C}$ for 48 hours anaerobically. Morphologically distinct and well isolated colonies were picked and transferred to new MRS plates by streaking. Finally, pure colonies were obtained and sent for biochemical characterization.

Experimental Design And Administration Of Lactobacillus Acidophilus To Clariasgariepinus

\begin{tabular}{|l|l|}
\hline GROUP & CONTENTS \\
\hline Control A1 & Conventional feed $+25 \mathrm{fish}+15$ litres of water \\
\hline Control A2 & Conventional feed $+25 \mathrm{fish}+15$ litres of water \\
\hline Experiment B 1 & Conventional feed $+25 \mathrm{fish}+15$ litres of water + L. acidophilus \\
\hline Experiment B2 & Conventional feed $+25 \mathrm{fish}+15$ litres of water + L. acidophilus \\
\hline
\end{tabular}

\section{Measurement Of Growth Performance And Survival Rates} Survival and Mortality rates

After 90 days of feeding experiment the fish were counted to determine the survival and mortality percentage according to the following formula:

i. Survival Rate $(\%)=$ Number of Fish at the End of the Experiment $\quad$ X 100

Number of Fish at the beginning of the Experiment

ii. Mortality rate $(\%)=$ Number of Fish that died during the experiment $\quad$ X 100

\section{Growth Performance}

Number of Fish at the beginning of the Experiment

Fish body weights per gram were recorded at the beginning (Day 1) and the end of the feeding experiment (Day 90) for all fish of each treatment to determine the difference between the initial and final weights of fish at 90days of experimental period. The following formulae were used to estimate the growth parameters:

a) Growth parameters

The following growth parameters were calculated:

i. Mean Weight Gain $(\mathrm{MWG})=$ Final mean weight $\left(\mathrm{W}_{1}\right)$ - Initial mean weight $\left(\mathrm{W}_{0}\right)$

ii. Average Daily Growth $(\mathrm{ADG})=$ Mean Weight Gained

Length of Feeding Trial (days)

iii. Percentage Weight Increase $(\mathrm{PWI})=\underline{\text { Mean Weight Gained }} \times 100$ Initial Mean Weight

iii. Specific Growth Rate $($ SGR $)=($ LnFinal Mean Weight - LnInitial Mean Weight $)$ Length of Feeding Trial (days)

\section{Results and Discussion}

The growth performance of fish in different experimental treatment were evaluated and the resulted are presented in Table 1 and Fig. 1 to 5. After 90 days, groups that received L. acidophilus showed increase in body weight in comparison with untreated control as it was tabulated in table Table 1 and graphically illustrated in Fig. 1 to 5 . Feed Conversion Rate after 90 days of feeding trial showed significant change in all treatments and control group with the following values, $0.07,0.09,0.09$ and 0.09 for the control group, groups A,B and C respectively (Fig. 3).

The results of Relative Growth Rate, Specific Growth rate, Average daily Weight Increase and were also evaluated after 90 days for groups that received L. acidophilus and untreated control group. The results of Relative Growth Rate, Specific Growth rate, Average daily Weight are presented in Fig.2, 3 and 5 respectively. The results indicated that the Specific growth rate in the groups that received L. acidophilus were higher than that of the control with the following values $1.77,1.89,1.91$ and 1.92 for the control, group A, group B and group C respectively(Fig. 3). The values obtained for Average Daily weight Gained for Group A, B and C were $3.5 \mathrm{~g}, 3.6 \mathrm{~g}$ and $3.6 \mathrm{~g}$ respectively while that of the control was $3.1 \mathrm{~g}$ (Fig 5). The mean values of the results obtained for RGR for Group A,B and C were $448.8,455.9$ and 463.06 respectively while that of the control was 
392.9(Fig.2). No significant difference was observed in the groups that were fed with L. acidophilus but totally different from that of the control.

The final weight of the groups that received L. acidophilus were not statistically different with the following mean values 390g, 395g and 400g for Group A ,B and C respectively(Table 1 and Fig 1) but the mean weight of the control that does not receive L. acidophilus was $350 \mathrm{~g}$ which is statistically different from the groups that received L. acidophilus at $\mathrm{P}<0.05$ (Table 1).

Figure 6 showed the results of percentage survival and mortality of fish after 90 days of feeding trial. The result obtained revealed that percentage of fish that survived in the groups fed with L. acidophilus were $84 \%, 88 \%$ and $88 \%$ for Group A,B and C respectively and $72 \%$ for the control that was not fed with $L$. acidophilus the corresponding percentage mortality was calculated to be $16 \%, 12 \%, 12 \%$ and $20 \%$ respectively. The result indicated that percentage mortality was very high in the control group that was not fed with $L$. acidophilus.

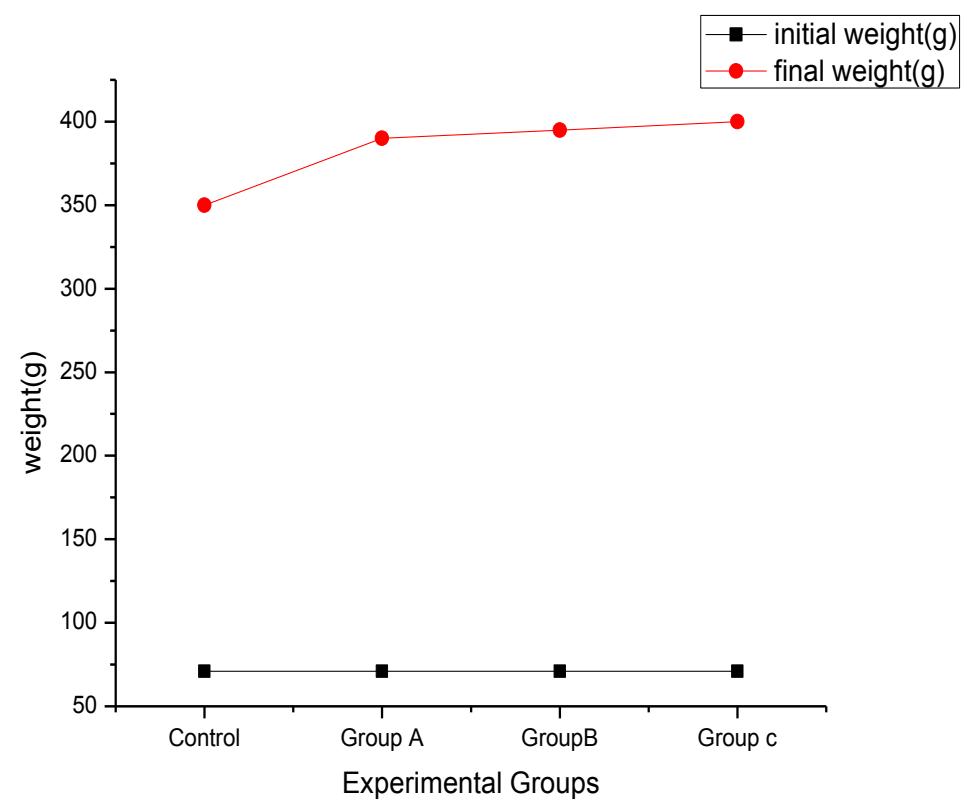

Fig.1: Comparison of initial and final weight of C. gariepinus after 90 days of feeding

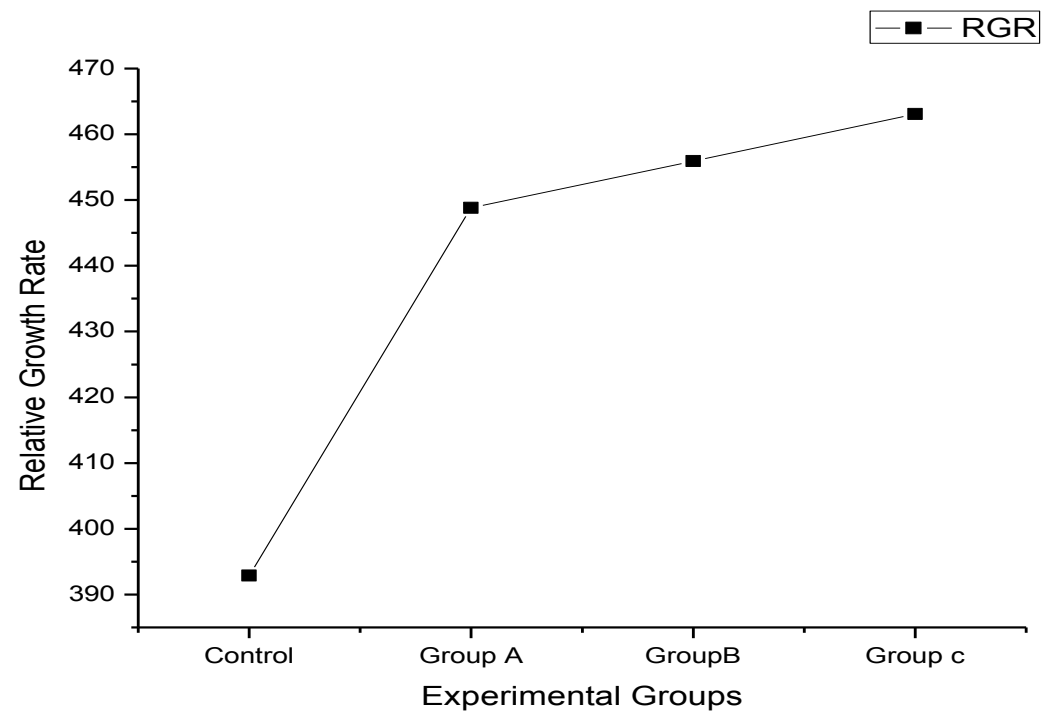

Fig.2: Relative Growth Rate of C. gariepinus after 90 days of feeding trial with L.acidophilus 


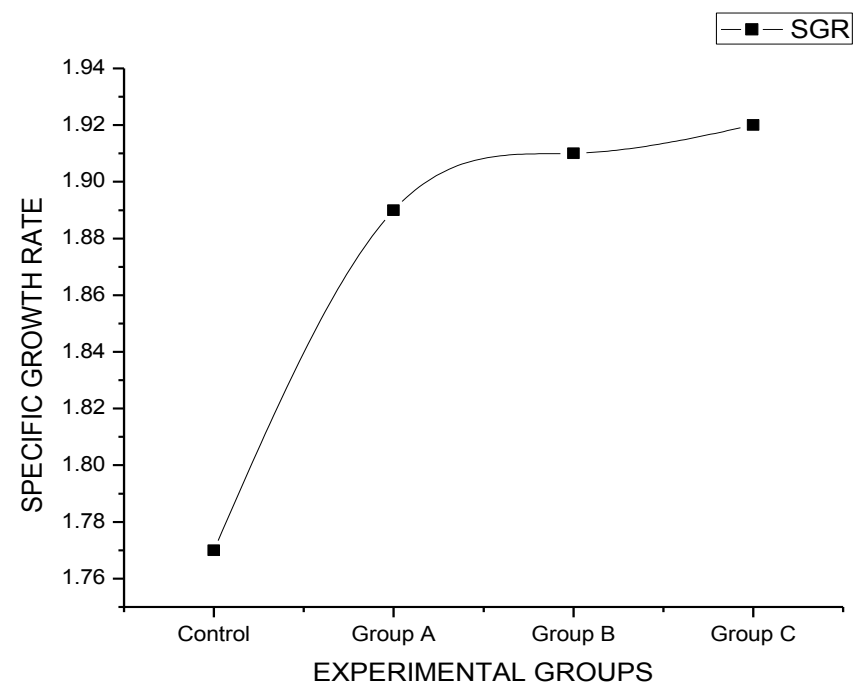

Fig.3: Effect of L.acidophilus on Specific growth rate ofC. gariepinusafter 90 days of feeding

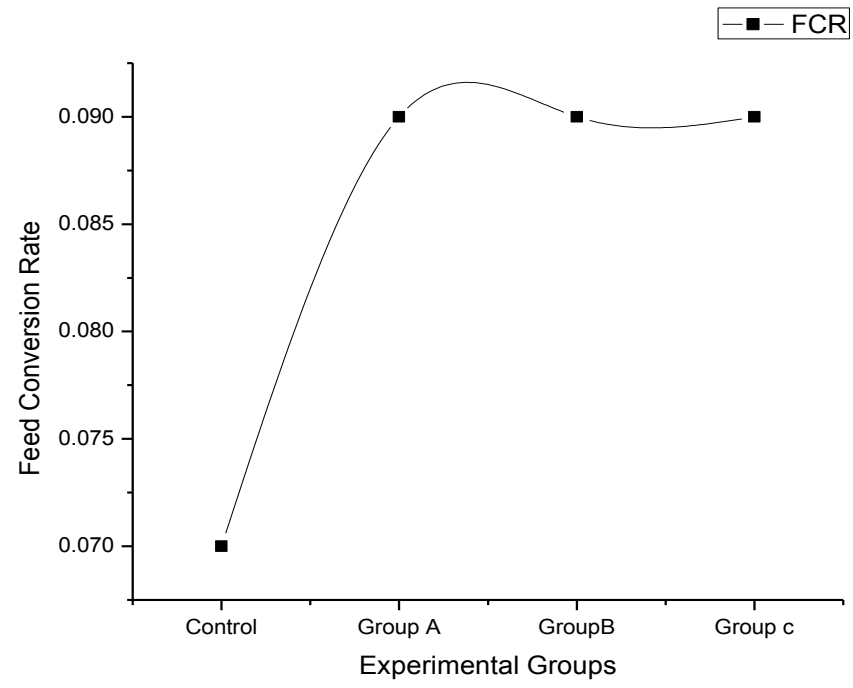

Fig.4: Effect of L.acidophilus on feed conversion rate of $C$. gariepinus after 90 days of feeding

\begin{tabular}{llll}
\hline \multicolumn{1}{c}{ Sample } & Mean Initial weight $(\mathbf{g})$ Wo & Mean final weight $(\mathbf{g}) \mathbf{W}_{\mathbf{1}}$ & $\begin{array}{c}\text { Mean } \\
\text { difference }(\mathbf{g})\end{array}$ \\
\hline Control & 71.00 & 350 & 279 \\
Group A & 71.06 & 390 & 318.94 \\
Group B & 71.05 & 395 & 323.95 \\
Group C & 71.04 & 400 & 328.96 \\
\hline
\end{tabular}

Table 1: Effect of L. acidophilus on body weight of $C$. gariepinus after 90 days of feeding 


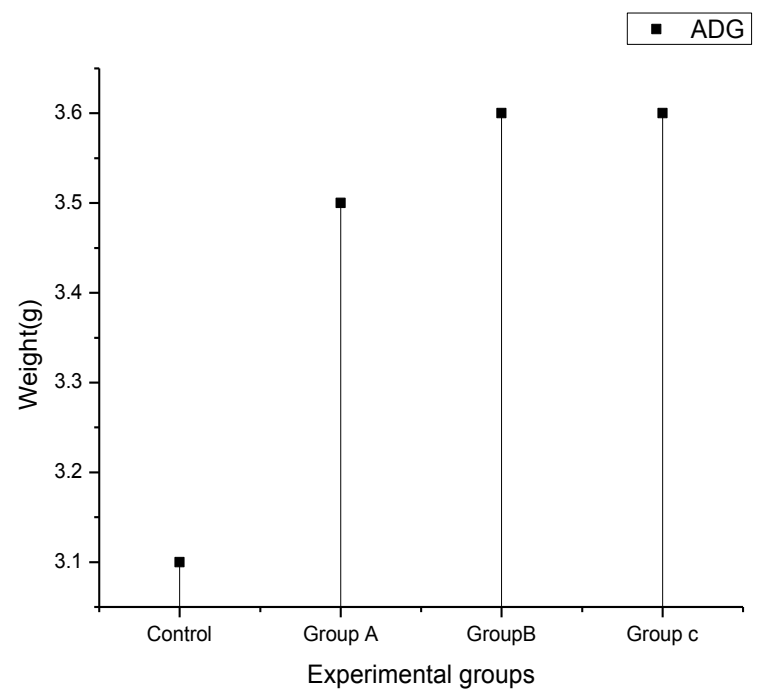

Fig. 5: Mean value of average daily weight gain of $C$. gariepinus for a period of 90 days.

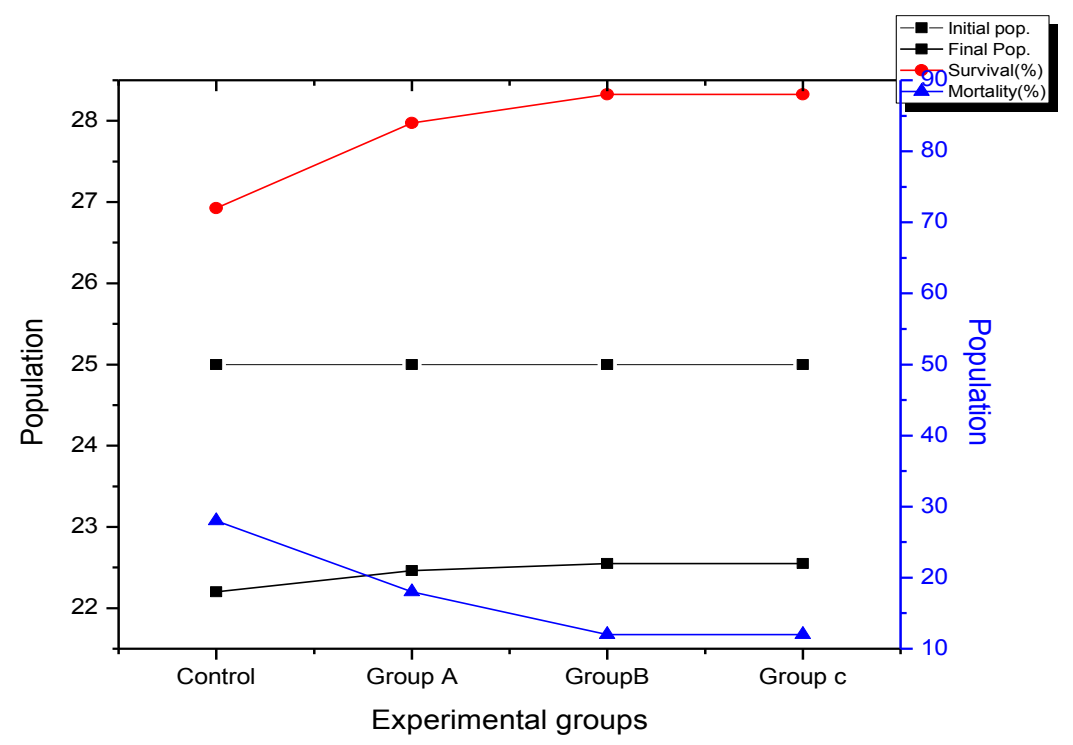

Fig. 6: Mortality and survival rates of C. gariepinus for 90 days of feeding.

\section{Discussion}

The results obtained from this study were in line with the report of [7]that showed that the use of $L$. delbrueckii as probiotic had positive effects on welfare and growth of sea bass juveniles. Their report indicated that probiotics decreased cortisol levels of treated animals and affected the transcription of two genes involved in the regulation of body growth, IGF-I and MSTN. In particular, IGF-I transcription was increased and MSTN transcription was inhibited in treated groups. All the mentioned changes resulted in a sharp increase of body weight of treated animals.

Another report that corroborated the findings of this result is the result obtained by [8] who examined the effects of a commercial Bacillus probiotic on the digestive enzyme activity, survival and growth of Fenneropenaeus indicus at various ontogenetic stages. and shrimp that had received probiotic exhibited significant $(\mathrm{P}<0.05)$ increases in both survival $(11-17 \%$ higher $)$ and wet weight $(8-22 \%$ higher $)$ as compared to controls. Probiotic was administered during both the hatchery stages and the farming stages, the feed conversion ratio, specific growth rate, and final production were slightly, but significantly higher in shrimp receiving the probiotic than in control shrimp which had received no probiotic. Because these improvements in growth parameters in post larval shrimp were significant only in shrimp that had received the probiotic both during hatchery stages and during farming stages, it appears to be important for the shrimp to receive the probiotic in all ontogenetic stages in order for these improvements to be realized. 
Similarly,[9]evaluated Bacillus subtilis, for its probiotic potential in Indian major carp, Labeo rohita. Labeo rohita $(15 \pm 2 \mathrm{~g})$ were fed a feed containing B. subtilis in three concentrations for 2 weeks, e.g., 0.5 (T2), 1.0 (T3) and 1.5 (T4) $\times 10^{7} \mathrm{CFU}$ g 1 feed. The control group (T1) was fed feed without B. subtilis for the same period. The B. subtilis-treated fish (T4, $1.5 \times 10^{7} \mathrm{CFU} \mathrm{g}-{ }^{1}$ feed) showed maximum percent survival $(87.50 \%)$, weight gain $(35.5 \%)$. [10]evaluated the effects of probiotics on growth, of Japanese flounder Paralichthys olivaceus in a closed recirculating system. Survival and growth of flounder treated by supplying commercial probiotics either in the diet (the probiotic diet group), or into the rearing water (the water supply group), were higher compared to the untreated group (the control group).

Increase in weight was also reported by [11] in his study on the effect of probiotics (Photosynthetic bacteria and Bacillus sp) on growth performance and digestive enzyme activity of the shrimp Penaeus vannamei. Probiotics were added to shrimp basal diets as probiotics at three concentrations: T-1, $2 \mathrm{~g} \mathrm{~kg}^{-1}(1 \mathrm{~g}$ $\mathrm{kg}^{-1}$ lyophilized photosynthetic bacteria cells (PSB) and $1 \mathrm{~g} \mathrm{~kg}^{-1}$ lyophilized Bacillus sp. (BS)); $\mathrm{T}-2,10 \mathrm{~g} \mathrm{~kg}^{-1}$ (5 $\mathrm{g} \mathrm{kg}^{-1} \mathrm{PSB}$ and $\left.5 \mathrm{~g} \mathrm{~kg}^{-1} \mathrm{BS}\right)$; and T-3, $20 \mathrm{~g} \mathrm{~kg}^{-1}\left(10 \mathrm{~g} \mathrm{~kg}^{-1}\right.$ PSB and $\left.10 \mathrm{~g} \mathrm{~kg}^{-1} \mathrm{BS}\right)$. After 28 days, shrimp receiving the diets supplemented with probiotics showed significantly better growth performance than those fed the basal diet (Control).

[12]investigated the effect of Bacillus subtilis bacterium, on larval growth and development rate of Macrobrachium rosenbergii (de Man). Newly hatched larvae of $M$. rosenbergii were reared with two dietary treatments consisting of newly hatched Artemia Salina nauplii with B. subtilis $\left(10^{8}\right.$ cells $\left.\mathrm{ml}^{-1}\right)$, and newly hatched A. salina nauplii without B. subtilis carried out in triplicate in $60-\mathrm{L}$ aquarium $(50 \mathrm{~L})$. After trial, the larvae that fed B. subtilis-treated Artemia naupli were found to have higher survival and a faster rate of metamorphosis than larvae that were fed with nontreated Artemia naupli. There were significant differences between B. subtilis-treated Artemia naupli and nontreated Artemia diet in larval growth and development rate of metamorphosis $(\mathrm{P}<0.05)$. Larval survival after 40 days was significantly greater $(\mathrm{P}<0.05)$ in the B. subtilistreated groups $(55.3 \pm 1.02)$ compared with the nontreated groups $(36.2 \pm 5.02 \%)$.

\section{Conclusion and recommendations}

From the results obtained in this study it was obvious that feeding L. acidophilus to C. gaariepinus resulted in increased in the values of haematological parameters and this is an indication that $L$. acidophilus has positive role to play in the maintenance of fish health especially $C$. gariepinus. This study was able to establish that $L$. acidophilus could be a good probiotic candidate in fish production .

\section{References}

[1]. Kolndadacha. O. D., Adikwu, I. A., Okaeme A. N., Atiribom R. Y., Mohammed A and Musa Y. M. (2011): The role of probiotics in aquaculture in Nigeria. Continental j. Fisheries and Aquatic Science5 (1):8-15

[2]. Verschuere, L., Romout, G., Sorgeloos, P. and Verstrate, W. (2000): Probiotic bacteria as Biologcal control agents in aquaculture. Microbiology and Molecular Biology Reveiws, 64(4): 65-671.

[3]. Irianto A, Austin B (2002). Use of probiotics to control furunculosis in rainbow trout, Oncorhynchus mykiss (Walbaum). J. Fish Dis. 25 : $333-342$.

[4]. Strom E and Ringo E. (1993): Changes in bacterial floral in developing cod, Gadusmorhua L. Larvae after inoculation of Lactobacullusplantarum in the water In: physiological and biochemical aspects of Fish larval development (ed by B. Walther and H. J. Fyhn),. 226-228. University of Bergen, Bergen Norway

[5]. Panigrahi, A. and Azad, I. S. (2007):Microbial intervention for better fish health in aquaculture: the Indian scenario. Fish Physiol. Biochem., 33:429-40,

[6]. Balcazar, L. J., Blas, I., Ruiz-Zarzuela, I., Cunningham D., Vendrell, D. and Muzquiz, L.J. (2006). The role of probiotics in aquaculture. Veterinary Microbiology 114:173-186

[7]. Carnevali, O., De Vivo, L., Sulpizio, R., Gioacchini, G., Olivotto, I., Silvi, S., and Cresci, A., (2006): Growth improvement by probiotic in European sea bass juveniles (Dicentrarchus labrax, L.), with particular attention to IGF-1, myostatin and cortisol gene expression . Aquaculture, 258 (1-4):430-438.

[8]. Ziaei-Nejad S., Rezaei M. H., Ghobad Azari Takami G. A., Lovett D. L., Ali-Reza Mirvaghefi A. and Shakouri M., (2006): The effect of Bacillus spp. bacteria used as probiotics on digestive enzyme activity, survival and growth in the Indian white shrimp Fenneropenaeus indicus. Aquaculture.

[9]. Kumar R., Mukherjee S. C., Prasad K. P. and Pal A. K. (2006): Evaluation of Bacillus subtilis as a probiotic to Indian major carp Labeo rohita (Ham.) Aquaculture Research 37 (12), 1215-1221.

[10]. Taoka Y, Maeda H, Jo J Y, Jeon MJ, Bai SC, Lee WJ, Yuge K, Koshio S. 2006: Growth, stress tolerance and non-specific immune response of Japanese flounder Paralichthys olivaceus to probiotics in a closed recirculating system. Fisheries Sci 72 (2): $310-321$.

[11]. Wang Y., (2007): Effect of probiotics on growth performance and digestive enzymeactivity of the shrimp Penaeus vannamei, Aquaculture 269: 259-264.

[12]. Keysami, M.A., Saad,C.R., Sijam, K., Daud, H.M. and Alimon, A.R. (2007): Effectof Bacillus subtilis on growth development and survival of larvae Macrobrachium rosenbergii (de Man) Aquaculture Nutrition 13 (2), 131-136. 